\title{
PD-L1 expression in perihilar and intrahepatic cholangiocarcinoma
}

\author{
Jacqueline Fontugne ${ }^{1,2,3}$, Jérémy Augustinn ${ }^{1}$, Anaïs Pujals ${ }^{1,3}$, Philippe Compagnon ${ }^{3,4}$, \\ Benoit Rousseau ${ }^{2,3,5}$, Alain Luciani ${ }^{2,3,6}$, Christophe Tournigand ${ }^{3,5}$, Daniel Cherqui', \\ Daniel Azoulay ${ }^{3,4}$, Jean-Michel Pawlotsky ${ }^{2,3,8}$, Julien Calderaro ${ }^{1,2,3}$ \\ ${ }^{1}$ AP-HP, Groupe Hospitalier Henri Mondor, Département de Pathologie, Créteil, France \\ ${ }^{2}$ INSERM, U955, Team 18, Institut Mondor de Recherche Biomédicale, Créteil, France \\ ${ }^{3}$ Université Paris Est Créteil, Créteil, France \\ ${ }^{4}$ AP-HP, Groupe Hospitalier Henri Mondor, Département de Chirurgie Hépato-Biliaire et Transplantation Hépatique, Créteil, France \\ ${ }^{5}$ AP-HP, Groupe Hospitalier Henri Mondor, Département d'Oncologie Médicale, Créteil, France \\ ${ }^{6}$ AP-HP, Groupe Hospitalier Henri Mondor, Département d'Imagerie Médicale, Créteil, France \\ ${ }^{7}$ AP-HP, Centre Hépatobiliaire, Service de Chirurgie Hépatobiliaire, Hopital Paul Brousse, Créteil, France \\ ${ }^{8}$ AP-HP, Groupe Hospitalier Henri Mondor, Service de Virologie, Bactériologie-Hygiène, Mycologie-Parasitologie et Unité Transversale \\ de Traitement des Infections, Créteil, France
}

Correspondence to: Jacqueline Fontugne, email: fontugnej@gmail.com

Keywords: cholangiocarcinoma, $P D-1, P D-L 1$, immunotherapy

Received: August 02, $2016 \quad$ Accepted: February 12, 2017

Published: February 21, 2017

Copyright: Fontugne et al. This is an open-access article distributed under the terms of the Creative Commons Attribution License (CC-BY), which permits unrestricted use, distribution, and reproduction in any medium, provided the original author and source are credited.

\section{ABSTRACT}

Cholangiocarcinoma is an aggressive biliary neoplasm lacking effective therapeutic agents. Immunotherapies targeting the PD-L1/PD-1 immune checkpoint have shown encouraging results in solid and hematologic cancers in clinical trials. Response to these immunomodulators is correlated with PD-L1 expression. Our goal was to characterize PD-L1 expression in intra-hepatic (iCCA) and perihilar (PCCA) cholangiocarcinomas, and to correlate our results with clinicopathological features, density of tumor-infiltrating lymphocytes (TILs) and PD-1 expression.

A series of 58 iCCAs and 41 pCCAs was included in the study. PD-L1, PD-1 and CD3 expression was investigated using immunohistochemistry. Density of TILs was evaluated by immunohistochemistry using a quantitative score of CD3-stained intratumoral lymphocytes.

PD-L1 expression by neoplastic cells was observed in 9 cases ( $9 \%, 5$ iCCAs and 4 pCCAs). PD-L1 positive inflammatory cell aggregates were identified in $46 \%(n=46)$ of the cases (31 iCCAs and 15 pCCAs). PD-L1 expression by either neoplastic or inflammatory cells was associated to high density of CD3-positive TILs $(p=0.01$ and $p=0.005$, respectively). The number of PD-L1 positive inflammatory cell aggregates was higher in tumors with high PD-1 expression $(p<0.0001)$.

Altogether, PD-L1 in iCCA and PCCA is mainly expressed in tumors with high density of TILs. Our results suggest that CCAs with dense intratumoral lymphocytic infiltration might represent good candidates for PD-L1/PD-1 blocking agents.

\section{INTRODUCTION}

Cholangiocarcinomas represent a heterogeneous group of cancers derived from epithelial biliary cells. They are classified, according to their anatomic localization on the biliary tree, into intra-hepatic (iCCA), perihilar (pCCA) or distal cholangiocarcinomas [1]. Cholangiocarcinomas are characterized by high-level resistance to conventional anticancer agents and poor clinical outcome [2]. Surgical resection, the only curative treatment, is hampered by a high rate of tumor recurrence and a low overall 5-year survival rate [3]. New treatment strategies for cholangiocarcinoma therefore represent an urgent unmet need.

Recently, clinical trials using monoclonal antibodies targeting immune checkpoint regulators, such as Programmed- 
death-1 (PD-1) or its major ligand, Programmed-death Ligand 1 (PD-L1), showed promising results in various hematologic and solid cancers [4]. An objective response or prolonged disease stabilization were obtained in patients with advanced melanoma, bladder urothelial carcinoma, Hodgkin's lymphoma and renal cell, colorectal or non small-cell lung carcinomas [5-10].

Under physiological conditions, PD-L1 binding to the T-cell surface receptor PD-1 induces a downregulation of T-cell activation and signaling, as well as T-cell apoptosis, thereby suppressing auto-immunity $[11,12]$. PD-L1 protein can be expressed at the surface of macrophages and lymphocytes, but this is rarely the case in non-neoplastic epithelial tissues $[13,14]$. It has however been demonstrated that cancer cells can express PD-L1 to suppress the host's anti-tumor immune response and escape it $[11,13]$.

Multiple studies have sought to identify predictive markers of tumor response in order to select patients who would benefit most from immune checkpoint inhibitors $[7,15,16]$. Interestingly, tumor response to anti PD-L1 immunotherapies was reported to be strongly related to the tumoral expression of PD-L1 as assessed by immunochemistry [15, 17].

There is so far very little data on PD-L1 expression in cholangiocarcinoma $[15,18]$. Interim analysis of a phase 1 trial Keynote028 studying pembrolizumab, an anti-PD-1, in advanced cholangiocarcinoma or gallbladder carcinoma progressing after a first line therapy indicates that PD-L1 was positive in $42 \%(n=37 / 89)$ of patients. Nevertheless, to our knowledge, specific data on the type of PD-L1 expression (tumoral versus immune cells) and differences between intrahepatic, hilar and gallbladder cholangiocarcinoma were not yet communicated. Moreover, profile and incidence of PD-L1 expression may be different in early stage compared to advanced stage. Interestingly, $17 \%$ of responses were observed in this interim analysis [19].

This prompted us to investigate PD-L1 immunohistochemical expression in a series of iCCAs and pCCAs, and to correlate our findings with the clinical and pathological features of the tumors and PD-1 expression.

\section{RESULTS}

\section{Patients and samples}

Ninety-nine surgically resected cholangiocarcinomas were included in the study. The median age of the patients was 62.5 years (range 24 to 85 ) and the sex ratio (male/ female) was 2.09. Risk factors of liver disease were identified in 23 patients: hepatitis $B$ virus infection in 8 cases, alcohol in 6 , non-alcoholic steatohepatitis in 6 , hepatitis $\mathrm{C}$ virus infection in 1 , primary sclerosing cholangitis in 2 , and hemochromatosis in 2 . Two patients had multiple risks factors. The main clinical characteristics of the 99 patients are summarized in Table 1. Follow-up data were available in a limited number of cases and could not be used for statistical analysis.

\section{Histological examination}

The tumors were intra-hepatic in $59 \%$ of cases $(n=58)$ and perihilar in $41 \%(n=41)$. Tumor size ranged from 6 to $230 \mathrm{~mm}$ (mean $59.5 \mathrm{~mm}$ ) (Table 1). Tumors were well/moderately or poorly differentiated in $73 \%(n=72)$ and $27 \%(n=27)$ of cases, respectively (Table 1$)$. Invaded surgical margins, vascular invasion, perineural invasion, and lymph node metastases were observed in $41 \%$ $(n=41), 63 \%(n=62), 55 \%(n=55)$ and $54 \%(n=36 / 67)$ of tumors, respectively. Adjacent non tumoral liver fibrosis could be analyzed in all but one case and was graded as follows: F0-F1 in 45\% $(n=44), \mathrm{F} 2-\mathrm{F} 3$ in $47 \%(n=46)$ and F4 in $8 \%(n=8)$ of cases.

\section{Immunohistochemistry}

Density of CD3-positive intratumoral lymphocytic infiltration was evaluated in 98 cases and scored high in $57 \%$ of iCCAs $(n=33)$ and in $67 \%$ of pCCAs $(n=27 / 40)$ (Table 1).

PD-L1 expression by neoplastic cells was observed in a limited number of cases $(9 \%, n=9)$. PD-L1 positive tumors were intra-hepatic in 5 cases ( $9 \%$ of ICCAs) and perihilar in 4 cases ( $10 \%$ of pCCAs). The percentage of PD-L1 tumor cell expression ranged from 0 to $30 \%$. An almost significant relationship with poor differentiation and high PD-1 expression was observed ( $p=0.06$ and 0.05, respectively) (Table 2 and Figure 1).

Aggregates of PD-L1-positive inflammatory cells were identified in $46 \%(n=46)$ of cases, including 31 iCCAs and 15 pCCAs (Figure 1). The number of PDL1-positive aggregates per $10 \mathrm{HPFs}$ ranged from 0 to 67 (mean: $6.6 \pm 14$ ).

PD-L1 expression by either neoplastic or inflammatory cells was associated with high density of TILs ( $p=0.01$ and $p=0.005$, respectively) (Table 2).

The number of PD-L1 positive aggregates of inflammatory cells was also higher in tumors with high PD-1 expression $(p<0.0001)$ (Figure 2).

\section{DISCUSSION}

Cholangiocarcinoma is a highly aggressive neoplasm characterized by the lack of effective therapy and a dismal prognosis. Recent clinical trials using PDL1/PD-1 immune checkpoint blocking agents have shown efficacy in various malignancies, with responses strongly associated to PD-L1 expression, as assessed by immunochemistry [15]. In the present study, we evaluated the immunohistochemical expression of PD-L1 in a series of iCCAs and pCCAs, and compared our findings with the 
Table 1: Main clinical features of the patients and pathological characteristics of the tumors

\begin{tabular}{|c|c|c|}
\hline & $\operatorname{iCCA}(n=58)$ & $\operatorname{pCCA}(n=41)$ \\
\hline Age (median, range) & $62.5(33-85)$ & $62(24-78)$ \\
\hline Sex ratio $(M / F)$ & 1.9 & 2.4 \\
\hline \multicolumn{3}{|l|}{ Liver disease } \\
\hline None identified & 36 & 40 \\
\hline Hepatitis B virus infection & 7 & 1 \\
\hline Alcohol & 6 & 0 \\
\hline NASH & 6 & 0 \\
\hline Hemochromatosis & 2 & 0 \\
\hline Primary sclerosing cholangitis & 2 & 0 \\
\hline Hepatitis $\mathrm{C}$ virus infection & 1 & 0 \\
\hline Tumor size \pm SD $($ mean in $\mathbf{m m})$ & $73.4 \pm 37.4$ & $39.8 \pm 39.1$ \\
\hline \multicolumn{3}{|l|}{ Tumor differentiation } \\
\hline Well/moderately & $66 \%(38)$ & $83 \%(34)$ \\
\hline Poor & $34 \%(20)$ & $17 \%(7)$ \\
\hline Vascular invasion & $62 \%(36)$ & $63 \%(26)$ \\
\hline Perineural invasion & $33 \%(19)$ & $88 \%(36)$ \\
\hline Lymph node metastasis & $47 \%(15 / 32)$ & $60 \%(21 / 35)$ \\
\hline \multicolumn{3}{|c|}{ Density of tumor infiltrating lymphocytes $(n=98)$} \\
\hline High & $57 \%(33)$ & $67 \%(27 / 40)$ \\
\hline Low & $43 \%(25)$ & $33 \%(13 / 40)$ \\
\hline \multicolumn{3}{|l|}{ Non tumorous liver fibrosis } \\
\hline $\mathrm{F} 0-\mathrm{F} 1$ & $55 \%(31 / 57)$ & $32 \%(13)$ \\
\hline F2-F3 & $33 \%(19 / 57)$ & $66 \%(27)$ \\
\hline F4 & $12 \%(7 / 57)$ & $2 \%(1)$ \\
\hline
\end{tabular}

SD: standard deviation.

clinicopathological features of the tumors -including TILs density- and PD-1 expression.

We first observed that PD-L1 was mainly expressed by intratumoral immune cells in both iCCAs and pCCAs, with very few cases expressing PD-L1 in neoplastic cells. Sabbatino et al. studied PD-L1 and PD-1 expression in a series of 27 iCCAs and observed tumoral expression of PD-L1 in a higher proportion of cases than ourselves (30\%) [20]. However, the authors specified that tumors with "rare" staining were considered positive. This may suggest that they included cases with less than 5\% of tumor cell staining. Interestingly, in a recent meta- analysis of 27 clinical trials using PD-1/PD-L1 blocking agents, Gandini et al. showed that clinical trials using a $5 \%$ positivity cut-off for PD-L1 expression in tumor cells correlated with objective response, but the relationship was lost when a $1 \%$ positivity cut-off was used [21].

It is unknown whether PD-L1 expression by immune cells has the same predictive value on the response to therapy as its expression by tumor cells. It is now well established that intratumoral inflammatory cells may also contribute to $\mathrm{T}$ cell exhaustion and anti-tumor immunity suppression through PD-L1 expression [22, 23]. The relationship between PD-L1 and PD-1 expression reported here also supports the 
existence of a functional PD-L1/PD-1 immune checkpoint in cholangiocarcinoma. Moreover, as already reported in colorectal carcinoma, we observed enhanced PD-L1 expression by the microenvironment in cholangiocarcinomas with dense lymphocytic infiltrates, suggesting that these tumors stimulate the immune system and rely on the PD-L1/ PD-1 pathway to escape antitumor immunity $[24,25]$.
Altogether, this study shows that PD-L1 is mainly expressed by intratumoral inflammatory cells in both iCCAs and pCCAs, principally in tumors with dense intratumoral lymphocytic infiltration. Our results suggest that CCAs with dense intratumoral lymphocytic infiltration could be good candidates for PD-L1/PD-1 blocking agents.

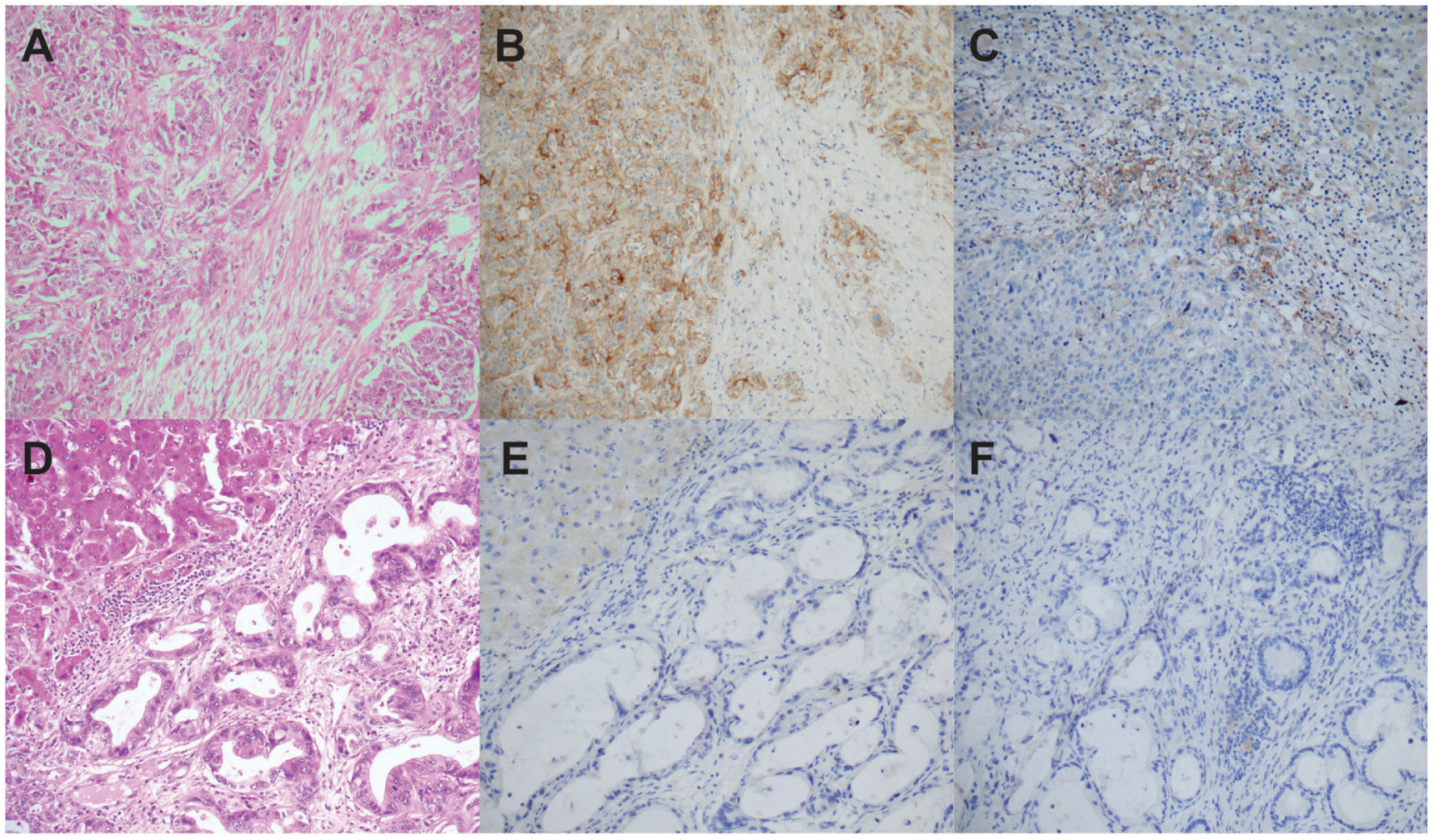

Figure 1: PD-L1 expression in cholangiocarcinoma. Poorly differentiated iCCA case showing a massive architectural pattern and no obvious glandular differentiation (hematein-eosin-saffron, X200) (A), membranous PD-L1 expression by the vast majority of neoplastic cells in this tumor area (X200) (B), and clusters of PD-L1-positive inflammatory cells (X200) (C). Well-differentiated iCCA case characterized by a glandular architectural pattern (hematein-eosin-saffron, X200) (D), no PD-L1 expression by neoplastic cells (X200) (E) or by inflammatory cells (X200) (F).
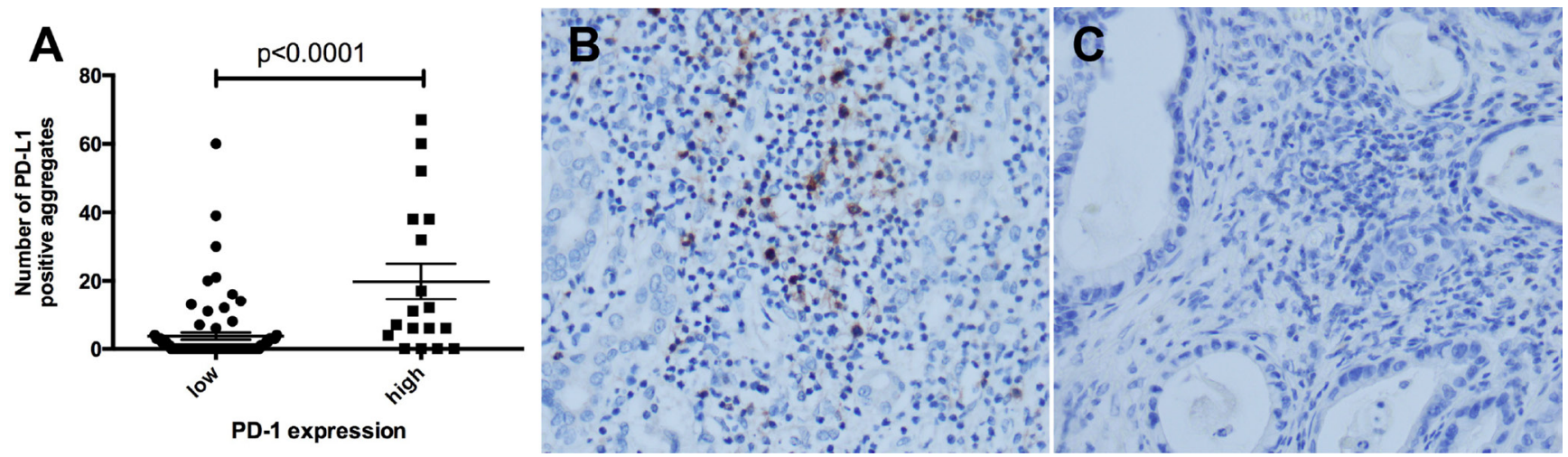

Figure 2: PD-L1 expression by inflammatory cells is significantly higher in PD-1 high tumors. Number of PD-L1 positive inflammatory cell aggregates in tumors with low and high PD-1 expression $(p<0.0001)(\mathbf{A})$. Representative micrographs of high $(\mathbf{B})$ and low (C) PD-1 expression (X400). 
Table 2: Relationship between PD-L1 expression and the clinico-pathological characteristics of the tumors

\begin{tabular}{|c|c|c|c|c|c|}
\hline & $\begin{array}{l}\qquad 5 \% \\
\text { PD-L1-positive } \\
\text { tumor cells }\end{array}$ & $\begin{array}{c}\quad \leq 5 \% \\
\text { PD-L1-positive } \\
\text { tumor cells }\end{array}$ & $p$-value & $\begin{array}{l}\text { PD-L1-positive } \\
\text { inflammatory cell } \\
\text { aggregates } \\
(\text { mean } \pm \text { SD) }\end{array}$ & $p$-value \\
\hline \multicolumn{6}{|l|}{$\overline{\text { Age }}$} \\
\hline$>62 \mathrm{yrs}$ & 3 & 46 & 0.49 & $5.7 \pm 10.6$ & 0.88 \\
\hline$\leq 62 \mathrm{yrs}$ & 6 & 44 & & $7.5 \pm 16.6$ & \\
\hline \multicolumn{6}{|l|}{ Sex } \\
\hline Male & 7 & 60 & 0.71 & $7.3 \pm 14.8$ & 0.51 \\
\hline Female & 2 & 30 & & $5.2 \pm 12$ & \\
\hline \multicolumn{6}{|l|}{ Tumor location } \\
\hline Intrahepatic & 5 & 53 & 1 & $8.5 \pm 16.7$ & 0.14 \\
\hline Perihilar & 4 & 37 & & $3.9 \pm 8.3$ & \\
\hline \multicolumn{6}{|l|}{ Tumor size } \\
\hline$>50 \mathrm{~mm}$ & 3 & 46 & 0.49 & $8.3 \pm 16.6$ & 0.37 \\
\hline$\leq 50 \mathrm{~mm}$ & 6 & 44 & & $5.1 \pm 10.9$ & \\
\hline \multicolumn{6}{|c|}{ Tumor differentiation } \\
\hline Well/moderately & 4 & 68 & 0.06 & $9.5 \pm 17.4$ & 0.20 \\
\hline Poor & 5 & 22 & & $5.5 \pm 12.4$ & \\
\hline \multicolumn{6}{|c|}{$\begin{array}{l}\text { Density of tumor-infiltrating } \\
\text { lymphocytes }(n=98)\end{array}$} \\
\hline High & 9 & 51 & 0.01 & $10.0 \pm 16.9$ & 0.005 \\
\hline Low & 0 & 38 & & $1.5 \pm 3.3$ & \\
\hline \multicolumn{6}{|l|}{ Vascular invasion } \\
\hline Present & 5 & 57 & 0.72 & $7.7 \pm 9$ & 0.93 \\
\hline Absent & 4 & 33 & & $4.9 \pm 16.2$ & \\
\hline \multicolumn{6}{|c|}{ Perineural invasion } \\
\hline Present & 6 & 49 & 0.73 & $6.7 \pm 14$ & 0.29 \\
\hline Absent & 3 & 41 & & $6.6 \pm 14$ & \\
\hline \multicolumn{6}{|c|}{ Lymph node metastasis } \\
\hline Present & 4 & 32 & 1 & $8.0 \pm 15$ & 0.58 \\
\hline Absent & 3 & 28 & & $4.1 \pm 13.4$ & \\
\hline \multicolumn{6}{|l|}{ PD-1 expression } \\
\hline High & 4 & 14 & 0.05 & $19.7 \pm 22.2$ & $<0.0001$ \\
\hline Low & 5 & 76 & & $3.8 \pm 9.3$ & \\
\hline
\end{tabular}

SD: standard deviation.

\section{MATERIALS AND METHODS}

\section{Patient population and specimen collection}

Patients included in the study underwent surgical resection for iCCA or pCCA at Henri Mondor Hospital, Créteil, France, between 1998 and 2015. Patients with combined hepatocellular-cholangiocarcinoma or with prior chemotherapy treatment were excluded.

Age, gender and risk factors of chronic liver disease were systematically recorded. Histological slides were retrieved from the Pathology Department archives. The study was approved by the Local Ethics Committee of SaintLouis Hospital, 'Ile de France IV' (IRB no. 00003835). 


\section{Histopathological analysis}

Three pathologists (J.F, J.A, J.C) reviewed all of the available hematein-eosin-saffron stained slides for each case. Diagnosis was confirmed according to the WHO classification system [26]. Each tumor specimen was analyzed for the following pathological parameters: tumor size, location (perihilar or intrahepatic) and degree of differentiation, perineural and vascular invasion, lymph node metastasis, and surgical resection margins. Non tumoral adjacent liver was evaluated for the degree of fibrosis according to the METAVIR scoring system [27].

One representative paraffin-embedded block representing the tumor area with the highest density of immune infiltration was selected. Although some representative slides included the tumor border, all immunohistochemistry stainings were evaluated strictly within the tumor, not at the tumor front.

\section{Evaluation of intratumoral lymphocytic infiltration density}

Density of intratumoral infiltrating lymphocytes was assessed on the representative tumor slide by immunohistochemistry using a polyclonal rabbit antihuman CD3 antibody (DAKO A0452). After examination of a training set comprising 35 tumors, CD3 expression was scored in the densest infiltrative areas within the tumor, by counting the number of high power fields (HPFs) $\left(\mathrm{X} 400,0.26 \mathrm{~mm}^{2}\right)$ with greater than $100 \mathrm{CD} 3-$ stained TILs. Tumors with less than 10 HPFs comprising at least $100 \mathrm{CD} 3+$ TILs were scored "low" and those with 10 or more were scored "high" for intratumoral lymphocytic infiltration density. CD3 staining could not be performed in one case due to block exhaustion.

\section{PD-L1 and PD-1 expression by immunohistochemistry}

All immunostainings were performed on $4 \mu \mathrm{m}$-thick whole sections of the representative tumor block, to avoid sampling heterogeneity inherent to tissue-microarray techniques. After deparaffinization and rehydration, antigen retrieval was performed in BondMax Epitope Retrieval buffers (Leica Biosystems, Nussloch, Germany) at $\mathrm{pH} 6$ (PD-1) or $\mathrm{pH} 9$ (PD-L1) with the primary antibodies Abcam AB52587 and Cell Signaling E1L3N, respectively. Immunodetection was performed with a biotin-conjugated secondary antibody (Vision BioSystems DS9713, Menarini, Florence, Italy) followed by peroxidase-labeled streptavidin and with diaminobenzidine chromogen as the substrate (Vision BioSystems DAB, Menarini). Slides were processed on an automated immunostainer (Leica Bondmax) according to the manufacturer's instructions. Anti-PD-L1 and anti-PD-1 antibodies were verified and calibrated on appropriate external positive control tissues, with known constitutive positivity. Placenta was used for PD-L1 (strong syncitiotrophoblastic cell positivity) and benign lymph node tissue for PD-1 (strong positivity of follicular helper T-cells).

PD-L1 expression was assessed in both tumor cells and tumor-infiltrating inflammatory cells. Tumor cells were considered PD-L1-positive in the presence of strong membranous staining (easily identified at X100) in at least $5 \%$ of tumor cells [28]. Inflammatory cells (macrophages and/or lymphocytes) expressing PD-L1 formed small aggregates interspersed within the tumor area, as previously reported in other malignancies [16, 29, 30]. We thus decided to assess PD-L1 expression in inflammatory cells by counting the number of positive clusters in 10 high-magnification fields $\left(\mathrm{X} 400,0.26 \mathrm{~mm}^{2}\right)$.

PD-1 was only expressed by lymphocytes, and its expression, after examination of a training set comprising 35 tumors, was assessed in 10 HPFs in intratumoral areas with the highest density of stained cells. Tumors with at least 5 HPFs comprising 20 or more PD- 1 stained lymphocytes were scored "PD-1 high", those with less were scored "PD-1 low".

\section{Statistical analysis}

Statistical analysis was performed using Graphpad Prism 6 Software. Continuous variables and proportions were compared using Mann-Whitney and Fisher exact tests, respectively. $p$ values $<0.05$ were considered statistically significant.

\section{ACKNOWLEDGMENTS}

The authors warmly thank the Plateforme des Ressources Biologiques and Tumorothèque of Henri Mondor Hospital.

\section{CONFLICTS OF INTEREST}

The authors have no conflicts of interest to disclose.

\section{GRANT SUPPORT} funding.

This research did not receive any specific grant or

\section{REFERENCES}

1. Razumilava N, Gores GJ. Cholangiocarcinoma. Lancet. 2014; 383:2168-79. doi: 10.1016/S0140-6736(13)61903-0.

2. Bridgewater J, Galle PR, Khan SA, Llovet JM, Park JW, Patel T, Pawlik TM, Gores GJ. Guidelines for the diagnosis and management of intrahepatic cholangiocarcinoma. J Hepatol. 2014; 60:1268-89. doi: 10.1016/j.jhep. 2014.01.021. 
3. Spolverato G, Kim Y, Ejaz A, Alexandrescu S, Marques H, Aldrighetti L, Gamblin TC, Pulitano C, Bauer TW, Shen F, Sandroussi C, Poultsides G, Maithel SK, et al. Conditional Probability of Long-term Survival After Liver Resection for Intrahepatic Cholangiocarcinoma: A Multi-institutional Analysis of 535 Patients. JAMA Surg. 2015; 150:538-45. doi: 10.1001/jamasurg.2015.0219.

4. Pardoll DM. The blockade of immune checkpoints in cancer immunotherapy. Nat Rev Cancer. 2012; 12:252-64. doi: $10.1038 /$ nrc3239.

5. Brahmer JR, Tykodi SS, Chow LQM, Hwu WJ, Topalian SL, Hwu P, Drake CG, Camacho LH, Kauh J, Odunsi K, Pitot HC, Hamid O, Bhatia S, et al. Safety and activity of anti-PD-L1 antibody in patients with advanced cancer. N Engl J Med. 2012; 366:2455-65. doi: 10.1056/ NEJMoa1200694.

6. Brahmer JR, Drake CG, Wollner I, Powderly JD, Picus J, Sharfman WH, Stankevich E, Pons A, Salay TM, McMiller TL, Gilson MM, Wang C, Selby M, et al. Phase I study of single-agent anti-programmed death-1 (MDX1106) in refractory solid tumors: safety, clinical activity, pharmacodynamics, and immunologic correlates. J Clin Oncol. 2010; 28:3167-75. doi: 10.1200/JCO.2009.26.7609.

7. Topalian SL, Hodi FS, Brahmer JR, Gettinger SN, Smith DC, McDermott DF, Powderly JD, Carvajal RD, Sosman JA, Atkins MB, Leming PD, Spigel DR, Antonia SJ, et al. Safety, activity, and immune correlates of anti-PD-1 antibody in cancer. N Engl J Med. 2012; 366:2443-54. doi: 10.1056/NEJMoa1200690.

8. Hamid O, Robert C, Daud A, Hodi FS, Hwu WJ, Kefford R, Wolchok JD, Hersey P, Joseph RW, Weber JS, Dronca R, Gangadhar TC, Patnaik A, et al. Safety and tumor responses with lambrolizumab (anti-PD-1) in melanoma. N Engl J Med. 2013; 369: 134-44. doi: 10.1056/NEJMoa1305133.

9. Ansell SM, Lesokhin AM, Borrello I, Halwani A, Scott EC, Gutierrez M, Schuster SJ, Millenson MM, Cattry D, Freeman GJ, Rodig SJ, Chapuy B, Ligon AH, et al. PD-1 blockade with nivolumab in relapsed or refractory Hodgkin's lymphoma. N Engl J Med. 2015; 372:311-9. doi: 10.1056/NEJMoa1411087.

10. Powles T, Eder JP, Fine GD, Braiteh FS, Loriot Y, Cruz C, Bellmunt J, Burris HA, Petrylak DP, Teng S, Shen X, Boyd Z, Hegde PS, et al. MPDL3280A (antiPD-L1) treatment leads to clinical activity in metastatic bladder cancer. Nature. 2014; 515:558-62. doi: 10.1038/ nature13904.

11. Chen L. Co-inhibitory molecules of the B7-CD28 family in the control of T-cell immunity. Nat Rev Immunol. 2004; 4:336-47. doi: 10.1038/nri1349.

12. Pedoeem A, Azoulay-Alfaguter I, Strazza M, Silverman GJ, Mor A. Programmed death-1 pathway in cancer and autoimmunity. Clin Immunol. 2014; 153:145-52. doi: 10.1016/j.clim.2014.04.010.

13. Dong H, Strome SE, Salomao DR, Tamura H, Hirano F, Flies DB, Roche PC, Lu J, Zhu G, Tamada K, Lennon VA,
Celis E, Chen L. Tumor-associated B7-H1 promotes T-cell apoptosis: a potential mechanism of immune evasion. Nat Med. 2002; 8:793-800. doi: 10.1038/nm730.

14. Sharpe AH, Wherry EJ, Ahmed R, Freeman GJ. The function of programmed cell death 1 and its ligands in regulating autoimmunity and infection. Nat Immunol. 2007; 8:239-45. doi: 10.1038/ni1443.

15. Taube JM, Klein A, Brahmer JR, Xu H, Pan X, Kim JH, Chen L, Pardoll DM, Topalian SL, Anders RA. Association of PD-1, PD-1 ligands, and other features of the tumor immune microenvironment with response to anti-PD-1 therapy. Clin Cancer Res. 2014; 20:5064-74. doi: 10.1158/1078-0432.CCR-13-3271.

16. Herbst RS, Soria JC, Kowanetz M, Fine GD, Hamid O, Gordon MS, Sosman JA, McDermott DF, Powderly JD, Gettinger SN, Kohrt HEK, Horn L, Lawrence DP, et al. Predictive correlates of response to the anti-PD-L1 antibody MPDL3280A in cancer patients. Nature. 2014; 515:563-7. doi: 10.1038/nature14011.

17. Meng X, Huang Z, Teng F, Xing L, Yu J. Predictive biomarkers in PD-1/PD-L1 checkpoint blockade immunotherapy. Cancer Treat Rev. 2015; 41:868-76. doi: 10.1016/j.ctrv.2015.11.001.

18. Gani F, Nagarajan N, Kim Y, Zhu Q, Luan L, Bhaijjee F, Anders RA, Pawlik TM. Program Death 1 Immune Checkpoint and Tumor Microenvironment: Implications for Patients With Intrahepatic Cholangiocarcinoma. Ann Surg Oncol. 2016; 23:2610-7. doi: 10.1245/s10434-016-5101-y.

19. Bang YJ, Doi T, Braud FD, Piha-Paul S, Hollebecque A, Razak ARA, Lin CC, Ott PA, He AR, Yuan SS, Koshiji M, Lam B, Aggarwal R. 525 Safety and efficacy of pembrolizumab (MK-3475) in patients with advanced biliary tract cancer: Interim results of KEYNOTE-028. Eur J Cancer. 2015; 51:S112. doi: 10.1016/S09598049(16)30326-4.

20. Sabbatino F, Villani V, Yearley JH, Deshpande V, Cai L, Konstantinidis IT, Moon C, Nota S, Wang Y, Al-Sukaini A, Zhu AX, Goyal L, Ting DT, et al. PD-L1 and HLA Class I Antigen Expression and Clinical Course of the Disease in Intrahepatic Cholangiocarcinoma. Clin Cancer Res. 2016; 22:470-8. doi: 10.1158/1078-0432.CCR-15-0715.

21. Gandini S, Massi D, Mandalà M. PD-L1 expression in cancer patients receiving anti PD-1/PD-L1 antibodies: A systematic review and meta-analysis. Crit Rev Oncol Hematol. 2016; 100:88-98. doi: 10.1016/j.critrevonc.2016.02.001.

22. Krempski J, Karyampudi L, Behrens MD, Erskine CL, Hartmann L, Dong H, Goode EL, Kalli KR, Knutson KL. Tumor-infiltrating programmed death receptor-1+ dendritic cells mediate immune suppression in ovarian cancer. J Immunol. 2011;186: 6905-13. doi: 10.4049/ jimmunol.1100274.

23. Ohaegbulam KC, Assal A, Lazar-Molnar E, Yao Y, Zang X. Human cancer immunotherapy with antibodies to the PD-1 and PD-L1 pathway. Trends Mol Med. 2015; 21:24-33. doi: 10.1016/j.molmed.2014.10.009. 
24. Friedman K, Brodsky AS, Lu S, Wood S, Gill AJ, Lombardo K, Yang D, Resnick MB. Medullary carcinoma of the colon: a distinct morphology reveals a distinctive immunoregulatory microenvironment. Mod Pathol. 2016; 29:528-41. doi: 10.1038/modpathol.2016.54.

25. Le DT, Uram JN, Wang H, Bartlett BR, Kemberling H, Eyring AD, Skora AD, Luber BS, Azad NS, Laheru D, Biedrzycki B, Donehower RC, Zaheer A, et al. PD-1 Blockade in Tumors with Mismatch-Repair Deficiency. $\mathrm{N}$ Engl J Med. 2015; 372:2509-20. doi: 10.1056/ NEJMoa1500596.

26. IARC, Bosman FT, Carneiro F, Hruban RH, Theise ND. WHO classification of tumours of the digestive system, Fourth Edition. World Health Organization. 2010.

27. Bedossa P, Poynard T. An algorithm for the grading of activity in chronic hepatitis $\mathrm{C}$. The METAVIR Cooperative Study Group. Hepatology. 1996; 24:289-93. doi:10.1002/ hep.510240201.
28. Weber JS, Kudchadkar RR, Yu B, Gallenstein D, Horak CE, Inzunza HD, Zhao X, Martinez AJ, Wang W, Gibney G, Kroeger J, Eysmans C, Sarnaik AA, et al. Safety, efficacy, and biomarkers of nivolumab with vaccine in ipilimumabrefractory or -naive melanoma. J Clin Oncol. 2013; 31:4311-8. doi: 10.1200/JCO.2013.51.4802.

29. Schultheis AM, Scheel AH, Ozretić L, George J, Thomas RK, Hagemann T, Zander T, Wolf J, Buettner R. PD-L1 expression in small cell neuroendocrine carcinomas. Eur $\mathrm{J}$ Cancer. 2015; 51:421-6. doi: 10.1016/j.ejca.2014.12.006.

30. Calderaro J, Rousseau B, Amaddeo G, Mercey M, Charpy C, Costentin C, Luciani A, Zafrani ES, Laurent A, Azoulay D, Lafdil F, Pawlotsky JM. PD-L1 expression in hepatocellular carcinoma: Relationship with clinical and pathological features. Hepatology. 2016; 64:2038-2046. doi: 10.1002/hep. 28710 . 